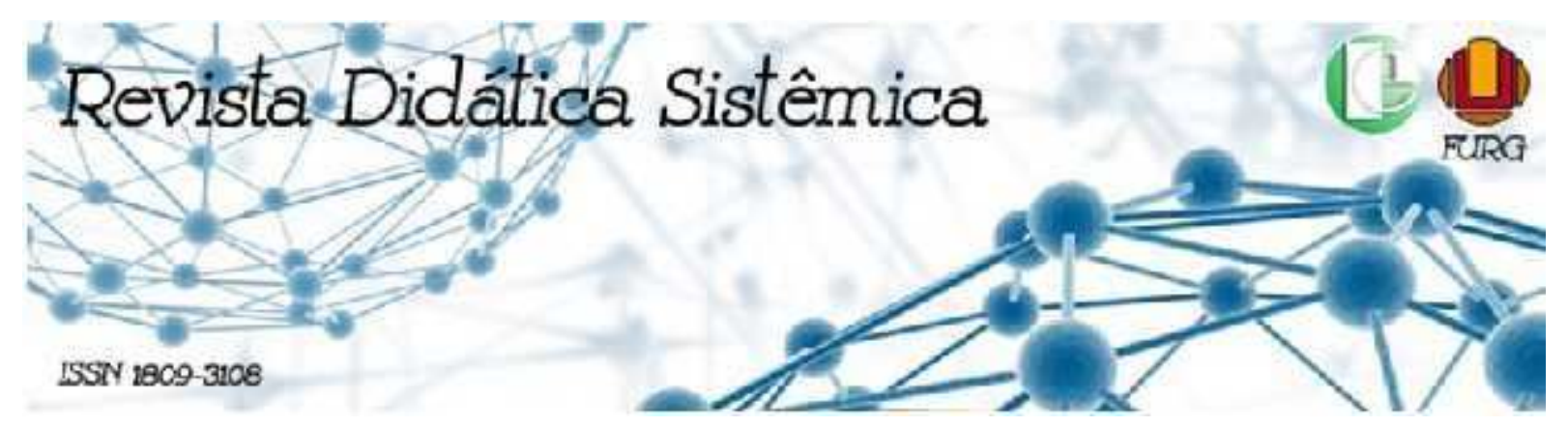

\title{
PESQUISAS COM CRIANÇAS: DEIXAR FAZER VIVER A VIVA VOZ DAS CRIANÇAS ${ }^{1}$
}

\author{
Altino José Martins Filho ${ }^{2}$ \\ Lourival José Martins Filho ${ }^{3}$
}

\section{RESUMO}

Este artigo reflete algumas questões em torno dos desafios e das possibilidades de desenvolver pesquisas com crianças pequenas. O objetivo principal é apontar aspectos do debate emergente em conhecer e revelar as peculiaridades, idiossincrasias e subjetividades que marcam a categoria social, cultural, classe e geracional infância. Pretendemos trazer algumas dúvidas e impasses teórico-metodológicos que se apresentam em relação à imagem de criança ligada à natureza, pura e inocente, que está presente em nossas representações imaginária. Não há, portanto, a pretensão de formular respostas definitivas às questões que se apresentam, mas suscitar temas e polêmicas imbricados com o campo dos Estudos das Crianças.

Palavras-chave: Pesquisa com Crianças; Formação Docente; Culturas Infantis; Participação; Minúcias da Vida Cotidiana.

\section{ABSTRACT}

This article reflects some questions surrounding the challenges and possibilities of developing research with young children. The main objective is to point out aspects of the emerging debate in knowing and revealing the peculiarities, idiosyncrasies and subjectivities that mark the social, cultural, class and generational childhood category. We intend to bring some doubts and theoretical-methodological

\footnotetext{
${ }^{1}$ Este artigo corresponde aos estudos de Altino José Martins Filho, realizados em estágio de pós-doutoramento (2019-2020), no Programa de Pós-Graduação em Educação, da Universidade do Estado de Santa Catarina - UDESC/FAED/PNPD/CAPES, na supervisão do Professor Dr ${ }^{\circ}$ Lourival José Martins Filho, vinculado ao Grupo de Pesquisa Didática e Formação Docente/NAPE/UDESC/FAED.

${ }^{2}$ Historiador (UFSC). Pedagogo (UNINOVE). Especialista em História Social (UDESC). Mestre em Educação e Infância (UFSC). Doutor em Educação (UFRGS), com ênfase em Estudos sobre Infâncias. Estágio de doutoramento na UMINHO/Portugal. Professor efetivo de Educação Infantil na Rede Municipal de Ensino de Florianópolis. Pós-doutorando UDESC/PPGE/PNPD/CAPES, vinculado ao Grupo de Pesquisa Didática e Formação Docente/NAPE.

E-mail: altinojosemartins@gmail.com

${ }^{3}$ Pedagogo (UDESC); Especialista em Alfabetização (UDESC). Mestre em Educação e Cultura (UDESC). Doutorado em Teologia com ênfase em Educação e Religião pela Escola Superior de Teologia - EST/RS. PósDoutorado em Educação e Religião na Escola de Educação e Humanidades da Pontifícia Universidade Católica do Paraná. Na UDESC/FAED, é Professor Associado de Alfabetização e Estágio Curricular Supervisionado nos Anos Iniciais do Ensino Fundamental. Leciona no Departamento de Pedagogia, no Programa de Pós-Graduação em Educação - Mestrado e Doutorado, e no Programa de Pós-Graduação em Gestão da Informação - Mestrado Profissional. Coordena o Programa de ensino, pesquisa e extensão Caminhos. É Coordenador Institucional do Programa Residência Pedagógica. É Coordenador de Pós-Graduação da UDESC. E-mail: f2lourival@udesc.br
} 
impasses that are presented in relation to the image of children linked to nature, pure and innocent and that is present in our imaginary representations. Therefore, it is not intended to formulate definitive answers to the questions presented, but to raise themes and controversies that are intertwined with the field of Children's Studies.

Keywords: Research with Children; Teacher Training; Childhood Cultures; Participation; Minutiae of Everyday Life.

(...) Há entre o mundo dos adultos e o das crianças como que um mar tenebroso, impedindo a comunicação.

(ROGER BASTIDE, 2004)

Faz tempo que os autores deste artigo estão perseguindo o interesse em afirmar a importância de desenvolver pesquisas com crianças. Temos dito que pesquisar as crianças é o caminho mais direto para conhecer e revelar as peculiaridades, idiossincrasias e subjetividades que marcam a categoria social, cultural, classe e geracional infância. Tal empreitada sublinha a afirmativa que considera a infância uma categoria geracional, com particularidades inerentes a ser pesquisada e conhecida por mérito próprio.

Resultados de pesquisas mais recentes apontam que a história da criança e da infância sempre foi construída "sobre a criança" e não "com a criança" (MARTINS FILHO, 2011; FERREIRA, 2002; 2003; 2004), na medida em que ela não tem uma fala considerada como legítima na ordem de pensar suas próprias necessidades de criança, ou quando os adultos desconsideram o que as crianças querem porque precisam. A criança está sob uma ótica infantil, suas manifestações são consideradas "engraçadinhas", ou "até mesmo servem para alegrar os adultos”, porém são infantilizadas e destituídas de razão.

Partindo dessa perspectiva, a imagem de criança ligada à natureza, pura e inocente, que está presente em nossas representações imaginárias, precisa ser constantemente repensada, tomando, como base, nossas ferramentas teóricas e os movimentos que se organizam no âmbito social.

Pode parecer demasiadamente reiterativa a escrita deste texto, porque nos parece importante insistir em algumas premissas que temos difundido quando à questão é: pesquisas com crianças. Mas isso também faz parte dessa estratégia geral dedicada a fazer soar nossa defesa em prol do protagonismo e da participação das crianças no mundo e na cultura humana, a mostrar algumas de suas dimensões, a assinalar suas heterogeneidades, destacar algumas de suas possibilidades precisas, ainda que, às vezes, a lógica da exposição pareça um tanto circular em relação ao que já foi dito em outras escritas (MARTINS FILHO, 2011; 2010; MARTINS 
FILHO e MARTINS FILHO, 2013; 2019). Se parece repetitivo escrever sobre a infância como categoria singular, cabe lembrar que as crianças, em nossa sociedade, foram os últimos sujeitos a serem reconhecidos como sendo construídos historicamente. Em relação às crianças serem produtoras de culturas, ainda temos muito a problematizar, estudar, refletir e categorizar teoricamente.

Dessa forma, as palavras de Roger Bastide, sociólogo francês, que orientou um importante trabalho no Brasil, na década de 1940, de outro sociólogo brasileiro, Florestan Fernandes, são significativas quando afirmamos a distância existente entre a categoria geracional adultez e a categoria geracional infância. Para nós, tal distanciamento em muito prejudica a comunicação e as interações entre sujeitos tão diferentes, adultos e crianças, mas, ao mesmo tempo, tão interligados, seja pela cultura, seja pelos processos de socialização. Vale a pena fazer referência à reflexão na integra de Bastide (2004), isso devido a sua atualidade de pensamento:

(...) Há entre o mundo dos adultos e o das crianças como que um mar tenebroso, impedindo a comunicação. Que somos nós, para as crianças que brincam ao nosso redor, senão sombras? Elas nos cercam, chocam contra nós; respondem às nossas perguntas, num tom de condescendência, quando fingimos interessar-nos por suas atividades (...). E nós, os adultos, vivemos também dentro de nossas próprias fronteiras, olhamos as crianças brincar, repreendemo-las quando fazem muito barulho, ou, se deixamos cair sobre seus divertimentos um olhar amigo, não é para eles que olhamos, mas, através deles, para as imagens nostálgicas de nossa infância desaparecida. (BASTIDE, 2004, s/p) ${ }^{4}$

Temos que romper com a submissão e subalternidade em que as crianças estão colocadas. Talvez, vencer algumas banalidades em relação à infância. Criar consciência plena de seu ser e estar no mundo, conhecer formas de as crianças habitarem o mundo e de produzirem suas culturas próprias da infância, de um modo único, singular, particular, por isso, apontamos que é chegado o momento de aprendermos com as crianças o que as infâncias têm a nos dizer, é um trabalho que os adultos precisam fazer sobre eles mesmos. Como Iturra (1999) aponta:

(...) os adultos têm que entender que a criança tem uma mente própria que está a aprender, mas cujo objetivo é também enganar o adulto. Enganar naquelas coisas que conseguem porque a criança, saiba o adulto ou não, entende que o adulto não sabe tudo. Porque a criança é uma pessoa com a cabeça extremamente aberta (...). (ITURRA, 1999, p.13)

\footnotetext{
${ }^{4}$ Essa passagem está no Prefácio do livro "Folclore e Mudança Social na Cidade de São Paulo" de Florestan Fernandes, 2004.
} 
Nesse contexto, consideramos, de extrema necessidade, escrever sobre o tema de pesquisas com crianças, o que nos motivou a estarmos presentes neste dossiê. Só isso bastaria para justificar nosso artigo nesse conjunto de textos que defendem as pesquisas que tomam as crianças como informantes de si mesmas. Tomamos a infância como uma categoria geracional, não absolutamente autônoma em si mesma, mas que, por meio da investigação, se considera fundamental dar visibilidade às singularidades das crianças, sujeitos que preenchem e esvaziam, simultaneamente, essa categoria. Proposição que expressa em argumentos consensual que fazer pesquisas com crianças é algo emergente e urgente, que somente nas últimas décadas, do século passado e início deste século, vem tomando forma, força e vigor. Muito temos para pesquisar com crianças para evidenciar as singularidades que as mesmas buscam para viver a infância. Nesse sentido, o campo da pesquisa com crianças abre enormes possibilidades teóricas, críticas e práticas. É seguindo essa trilha que apontamos caminhos para deixar fazer viver a viva voz das crianças.

Ferreira (2003; 2010) assevera que, ainda, nos falta entender a infância, simultaneamente, como uma categoria sócio-histórica geracional, como uma estrutura geracional e como um espaço social dentro do qual as crianças, enquanto atores individuais e coletivos, empenhados em agir nos seus mundos de vida, se constituem ativamente como crianças. Para a autora, falta-nos desenvolver uma escuta sensível ao que as crianças estão comunicando em seus enunciados 5 .

(...) é preciso escutar para compreender o que elas (nos) dizem, a partir da auscultação da sua voz, onde a escuta das e com as crianças reclama, sobretudo, ensaiar(me) (n)uma nova atitude epistemológica, a da escuta sensível (BARBIER, 1993) que supõe uma inversão da atenção. Antes de situar uma pessoa no seu lugar, começa por reconhecê-la no seu ser, na sua qualidade de pessoa complexa. (FERREIRA, 2003, p. 152)

Reconhecer que estamos aprendendo a fazer pesquisas com crianças é dar visibilidade às falas infantis. Temos falado muito sobre o protagonismo das crianças e a potência de agir desses sujeitos de pouco idade, porém, ainda nos falta atravessar algumas fronteiras, como escreveu Bastide, na década de 1940; muito já avançamos, mas o mar tenebroso ainda nos amedronta e nos impede de, na relação com as crianças, ouvir sua força de desejo e sustentar

\footnotetext{
${ }^{5}$ Estamos utilizando esse termo com base nos pressupostos de da teoria baktiniana, da qual temos nos aproximado em nossos estudos mais recentes. Aqui, o conceito é retomado para referir-se à fala das crianças, mesmo os bebês que ainda não possuem desenvolvido a linguagem oral. Para Bakntin (2011, p. 261), autor russo, "o emprego da língua efetua-se em formas de enunciados (orais e escritos) concretos e únicos, proferidos pelos integrantes desse ou daquele campo da atividade humana". O autor assevera que o termo enunciado significa "ato de enunciar, de exprimir, transmitir pensamentos, sentimentos, etc. em palavras".
} 
sua radical alteridade em relação às expectativas e à padronização adultocêntrica.

Larrosa (2011), escrevendo sobre a alteridade da infância, nos diz que:

Se lhe chamo de "princípio de alteridade" é porque isso que me passa tem que ser outra coisa que eu. Não outro eu, ou outro como eu, mas outra coisa que eu. Quer dizer, algo outro, algo completamente outro, radicalmente outro. (LARROSA, p. 06, 2011).

Análogo à afirmação de Jorge Larrosa, procuramos indicar, localizar e anunciar o lugar que as crianças podem (e devem) ocupar nas pesquisas com a infância. Para nós, uma possibilidade, também, de destacar o protagonismo infantil e a alteridade das crianças, que acompanha a necessidade de se desenvolver pesquisas que investiguem quem são as crianças, no sentido de conhecê-las. O viés que perseguimos ultrapassa os limites de uma concepção descritiva sobre o desenvolvimento infantil, a qual se dá por etapas ou fases humanas, ou ainda, a ideia que compreende as crianças como simples sujeito a ser investigado, analisado ou interrogado. Sendo assim, surge, no âmbito das pesquisas educacionais, um tratamento científico às crianças pequenas, o que rompe com o esquecimento que as envolveu (ou envolve) na construção da história da própria infância.

Nos diferentes textos que já temos escrito sobre fazer pesquisas com crianças, muitos são os argumentos, na sua maioria, extraído do campo empírico, contextos educativos de educação infantil, em que reunimos argumentos sobre a necessidade de reconhecer o alto grau de protagonismo das crianças para informar sobre a infância; ou seja: o que as crianças querem viver porque precisam viver em seu tempo de criança. Desse ponto de vista, parece fundamental que as pesquisas com as crianças pequenas contemplem sua participação ativa, também reconhecendo-as como informantes diretos e não apenas como objeto desse processo. $\mathrm{O}$ que nos favorece afirmar que, atualmente, não devemos estar abertos somente às pesquisas sobre as crianças, mas sim apostar em ouvir as crianças para conhecermos a singularidade da infância.

Essas reflexões indicam a existência de singularidades sublimes que marcam a diferença em relação a fazer pesquisas com outros grupos geracionais. Em especial, precisamos vencer a força argumentativa que ainda vigora no mundo acadêmico-científico, no qual as crianças pertencem a um conjunto de negativos, onde lhes faltam tudo e, seriam os adultos, os únicos promotores de tais necessidades, isso se daria por meio da transmissão, completando e preenchendo esse conjunto de negativos. Assim, à medida que as crianças vão crescendo, vão adquirindo o que lhes falta, vão memorizando e escrevendo em folhas, até então em branco, modos de ser e agir no mundo, uma cultura pronta a ser adquirida. Temos, aqui, motivos 
suficientes para contrariar a máxima que vigora sobre a aprendizagem das crianças: as crianças aprendem quando os adultos lhe ensinam algo. Vencer esses argumentos que dominaram (e dominam) as pesquisas nas ciências naturais, sociais e educacionais não tem sido algo simples. Em especial, pela condição biológica das próprias crianças, pois não podemos negar que as mesmas se encontram em processo de crescimento, seja biológico, cultural, seja social. Tal condição humana tem colocado as crianças em uma escassez de possibilidades em participar e decidir sobre suas próprias vontades, necessidades e interesses.

Neste viés de pensamento, Kramer (2000) corrobora, ao afirmar que as narrativas das crianças sobre suas experiências culturais, que podem possibilitar a leitura de mundo que as próprias crianças desenvolvem como sujeitos da história e da cultura. Nas palavras da autora:

\begin{abstract}
Aprender com as crianças pode ajudar a compreender o valor da imaginação, da arte, da dimensão lúdica, da poesia de pensar adiante. Entender que as crianças têm um olhar crítico que vira pelo avesso a ordem das coisas, que subverte o sentido de uma história, que muda a direção de certas situações, exige que possamos conhecer nossas crianças, o que fazem, o que brincam, o que inventam, de que falam. E que possam falar mais. Se a história e a linguagem são dimensão fundamentais que dão humanidade aos sujeitos, se acreditamos que há uma história porque há uma infância do homem, podemos compreender melhor nossas crianças, compreender melhor nossa época, nossa cultura, a barbárie e as possibilidades de transformação. (KRAMER, 2000, p. 12-13).
\end{abstract}

Seria uma virada de concepção na própria relação com a compreensão do que seja a cultura humana. De como é produzida a cultura humana no processo da história dos humanos. Encontramos eco nos escritos de Paulo Freire quando diz que a cultura tem centralidade para compreender a complexidade humana. No caso da cultura das crianças, as reflexões do autor nos ajudam a caracterizar que toda produção humana, toda maneira de ser e estar no mundo, que pode se manifestar de forma material e simbólica, são demonstração das manifestações culturais das crianças. Nas palavras de Paulo Freire (1963):

A cultura como acrescentamento que o homem faz ao mundo que ele não fez. A cultura como resultado de seu trabalho. De seu esforço criador e recriador. O homem, afinal, no mundo e com o mundo, como sujeito e não como objeto. (...) descobri-se-ia criticamente agora, como fazedor desse mundo da cultura. Descobriria que ele, como o letrado, ambos têm um ímpeto de criação e recriação. (...) que cultura é toda criação humana. (FREIRE, 1963, p. 17).

No ano de 2010, organizamos um dossiê para a Revista Reflexão e Ação, da Universidade Santa Cruz do Sul/UNISC. Nesse trabalho, reunimos diferentes autores que escreveram sobre o tema "Das Pesquisas com Crianças ao Encontro da Infância Contemporânea", autores brasileiros e estrangeiros. Em um dos textos, Suely Amaral Melo 
(2010) nos indaga que:

É nova, entre nós, a preocupação em ouvir as crianças nas pesquisas em educação e novo, também, o enfrentamento desse desafio. De fato, essa nova atitude não depende de uma decisão simples. Ao contrário, a atitude de ouvir as crianças e considerá-las - seja em nossas práticas pedagógicas, seja em nossas pesquisas - só é possível à medida que superamos o conceito de criança que por longo tempo orientou nosso pensar e agir na educação das crianças, especialmente das crianças pequenas. $\mathrm{O}$ conceito de criança como alguém incapaz de aprender até atingir certo nível de desenvolvimento nasceu de uma visão adultocêntrica de criança pequena que a caracterizava predominantemente de um ponto de vista negativo, destacando suas incapacidades em comparação com os adultos, a limitação de sua experiência, a insuficiência de seus conhecimentos, a incapacidade de pensar logicamente, de controlar sua própria conduta.

Para tanto, como sugere a citação de Melo (2010), em especial, tendo como aporte teórico os fundamentos da perspectiva histórico-cultural, é preciso superar o conceito de criança que vem orientando o pensar e o agir nas práticas de pesquisas com a infância. Assim, quando Marcia Aparecida Goob e Cleriston Izidro dos Anjos, organizadores do presente dossiê, nos perguntam: que dilemas e desafios epistemológicos, metodológicos e éticos os pesquisadores e as pesquisadoras têm enfrentado quando se trata da produção de conhecimento científico a respeito das crianças e infâncias? Arriscamos a dizer que essa nova concepção de criança - compreendidos como sujeitos sociais e culturais, capazes de estabelecer relações que paulatinamente vão se ampliando e se tornando mais complexas com o mundo e com a cultura que a rodeia - desperta, no pesquisador da infância, a necessidade de conhecê-la em suas peculiaridades positivas.

Não se trata de apontar respostas, longe de nós querer se arriscar a tal façanha, mas há uma questão em emergência e urgência para que o pensamento científico, metodológico e ético possa reconhecer os dilemas e desafios das pesquisas com crianças. Qual seja? Para nós, diz respeito às escolhas de concepções e opções teóricas em relação à compreensão das crianças como sujeitos sociais e culturais, e a infância como categoria geracional e empírica. O reconhecimento dessas duas categorias - infância e crianças - como sendo analisável em suas particularidades e singularidades, para nós, poderia vencer a escassez das crianças a serem chamadas a participarem das pesquisas e da construção de suas próprias experiências. Tal reconhecimento poderia contribuir para constituir princípios educativos, epistemológicos, metodológicos e éticos para desenvolvermos pesquisas com crianças tecidas na variabilidade humana, entrelaçadas na dialogicidade, sem determinismos biológicos. Pois concordamos quando a produção literária (CHARLOT,1996) anuncia se as práticas informam as teorias, são as teorias que orientam as práticas. Indiscutivelmente, é preciso apropriação teórica, 
internalização de reflexão crítica e investigação da própria prática para embasar as pesquisas, em especial, considerando as crianças: sujeitos tão desconhecidos e tratados por naturalizações e essencialismos. Também, construir argumentos suficientes para informar que as crianças aprendem muito quando estão entre si, nas relações com seus pares, está aí plantada o que temos escrito sobre a complexidade da infância.

Sarmento (2013, p.133), utilizando-se dos parâmetros teóricos da Sociologia da Infância, ao conceber a infância e as crianças como uma condição histórica e socialmente situada, interroga: como defender, então, uma educação da infância modelada por uma concepção universal de criança, presa a modelos pedagógicos fixos, desfocada da análise sociológica das condições reais de existência da infância e da escuta sensível dos modos de ser e de comunicar das crianças na sua concretude?

Temos insistido, também, por meio da leitura dos pressupostos teóricos da Sociologia da Infância e da Abordagem Histórico-Cultural e de nossas experiências como professores e pesquisadores, no campo da educação infantil, desenvolvendo e defendendo a construção de uma Pedagogia da Infância, ou, mais especificamente falando, de uma Pedagogia da Educação Infantil, a ideia de que a infância sendo uma construção social, constituindo uma estrutura geracional universal presente em todas as sociedades humanas e que os modos, ou o lugar que a crianças ocupa no mundo, interferem decididamente em seu reconhecimento e estatuto de sujeito social e sujeito cultural. Sabemos que são conquistas já destacadas no campo teórico, porém ainda estão longe de estarem presentes e de serem afirmadas e precisas no campo da prática. Estamos dizendo que alguns conceitos estão instalados nos discursos, porém, na prática de conviver, pensar e fazer a educação das crianças pequenas ou desenvolver pesquisa com elas, temos muitas lacunas a vencer. No entanto, concordamos com Natália Fernandes (2009) quando escreve que é cada vez menos questionável a ideia de que:

(...) é necessário outro olhar sobre a infância: partindo das leituras que as crianças fazem acerca dos seus quotidianos e dos problemas sociais com que se confrontam, permite recentrar a atenção para as problemáticas que condicionam as suas vidas, que porventura poderão passar despercebidas aos olhares adultos, que olham a ordem social das crianças através de lentes adultas. (FERNANDES, 2009, p. 87)

Rever as concepções de como fazer pesquisas com crianças pequenas, no campo da Educação, ao nosso ver, requer um trabalho revolucionário na formação do próprio pesquisador. Uma mudança de paradigma e quebra de pensamentos ligados a uma cultura de fazer investigação sobre as infâncias hegemônica, a qual está ligada a um modelo canônico 
adultocêntrico desde sua gênese. Na educação formal das crianças, é forte a existência de práticas pedagógicas balizadas pela pedagogia normativa em uma visão de criança evolucionista e biologista, vendo-as como sujeitos de um processo natural, isto é, biologicamente determinado, acontecendo por acúmulo quantitativo no nível do indivíduo e não na relação social. É salutar, novamente, reafirmar: há, fortemente, um tendência que idealiza uma imagem de infância com contornos homogêneos e adultocêntricos, tal como já foi constatado pelos estudos clássicos de Bernard Charlot (1996). Nesse sentido, a escola e sua consequente educação, aqui incluímos as formas de fazer pesquisas com crianças, utiliza técnicas de coerção, esquadrinha o tempo e o espaço de cada sujeito, aprisiona o corpo e modela a alma. A submissão e a subalternidade das crianças correspondem à submissão dos adultosprofessores-pesquisadores que não conseguem lutar pela emancipação, seja nos processos de educação, seja nos processos de pesquisa.

Em uma outra coletânea que organizamos juntamente em parceira com Patricia Prado, da Universidade de São Paulo/USP, em 2011, chamamos atenção para as contradições, ambiguidades, tensões e imprevistos nas instituições de educação infantil de "complexidade da infância", pois as crianças participam, intensamente, do "ensaio das humanidades", e nós estamos aprendendo a penetrar no universo das crianças. E essa complexidade precisa ser compreendida pelos adultos que educam a criança. Especialmente, para conhecer as formas de humanidades que as crianças nos apresentam, as quais, como temos apontado, são muito diferentes das dos adultos. Escrevendo sobre essa complexidade do estar das crianças em contextos de vida coletiva, creches e pré-escolas, colocamos que tal complexo reverbera para as pesquisas com crianças.

Tal coletânea traz uma valiosa base teórica sobre o desenvolvimento de pesquisas com crianças. Tomando as crianças como sujeitos participantes das pesquisas, questionamos e problematizamos procedimentos, técnicas e instrumentos metodológicos utilizados com as crianças. Afirmamos que as pesquisas atuais protagonizadas com as crianças tornam-se grande fonte de informação e de conhecimento sobre a infância. Os autores, no conjunto de textos, alertam para o fato de o pesquisador refletir e superar alguns limites e desafios que se fazem necessários para o desenvolvimento desse campo investigativo novo e incipiente: definição de papel e do lugar da criança como protagonista da pesquisa; coerência nas concepções de criança e de infância; atitude de reflexividade investigativa para constante adequação dos procedimentos metodológicos.

Nesse sentido, debatemos as culturas infantis a partir de um enfoque multidisciplinar e interdisciplinar, reconhecendo a importância e a contribuição das diferentes áreas do conhecimento, 
implicadas na investigação da diversidade das culturas infantis em contextos sociais, históricos, educacionais e psicológicos diversos. Entendemos que as ciências sociais e humanas, segundo suas diferentes tradições acadêmicas, têm muito a contribuir com este debate recente em nosso País, tendo em vista o crescente interesse de pesquisadores oriundos de diversas áreas de conhecimento em destacar o lugar ocupado por crianças nas pesquisas, nas instituições educativas, nas políticas e na legislação. (MELO, 2010). O tema do reconhecimento das crianças, em suas singularidades, é amplo e abrange diversas dimensões em que as crianças estão postas.

Desse modo, essa perspectiva de olhar para as produções das crianças na cotidianidade das instituições educativas pode, ainda, contribuir para se "compreender o cotidiano para além da obviedade, da arbitrariedade e da obscuridade que o esvazia de sua complexidade, quando o necessário seria viabilizar a afirmação da sua singularidade no entretecer de sua diversidade pedagógica”. (MARTINS FILHO, 2013, p. 46).

Almejamos contribuir com outras compreensões sobre os seres humanos de pouca idade, pois os bebês e crianças pequenas aprendem entre si, como também podem ensinar as gerações mais velhas (GOTTLIEB, 2009, 2013; BROUGÉRE e ULMANN, 2012). Como refere Brougère e Ulmann (2012), o conceito de aprendizagem ainda é pouco utilizado para evocar o que as crianças ensinam umas às outras, assim como estamos longe de aceitar a ideia de que uma criança possa ensinar alguma coisa a um adulto. Nas pesquisas com crianças, encontramos eco para fundamentar posições teóricas, metodológicas e éticas que, em consonância com o que argumentam Brougére e Ulmann (2012), nos possibilitam criar uma gestão na afirmação da importância de estudos e pesquisas centrados nos contextos em que essas crianças convivem com os demais, questão fundamental, uma vez que, na interação com outros, as crianças se formam e se tornam seres humanos, integrantes de uma comunidade histórica, social e culturalmente estabelecida. (MARTINS FILHO e DELGADO, 2013, p. 14). Uma gestão que se articula em defender os diretos das crianças em viver suas infâncias! Gestão que defende necessário perceber, na criança, a criança.

Essa compreensão impulsiona uma mudança na concepção de criança que passa a ser considera e percebida como capaz de aprender desde pequena. Inicialmente, com as experiências perceptivas que permitimos que viva e, a partir daí, vai formando para si qualidades humanas, num complexo processo dialético que envolve, em última instância, três elementos essenciais: os objetos da cultura oferecidos à criança; a atitude mediadora dos adultos que cuidam e educam a criança - ou seja, a concepção de criança desses adultos que medeiam a relação da criança com a cultura - e a própria ação da criança. Nesse processo de educação do 
qual resulta a formação das qualidades humanas - de apropriação de qualidades humanas criadas pelos homens e mulheres que nos antecederam ao longo da história -, a criança tem um papel ativo. Considerando os três elementos constitutivos do processo de educação na escola a cultura como fonte das qualidades humanas historicamente acumuladas, os professores como mediadores do acesso das crianças à cultura e a própria criança (MELO, 2010). O que visa a conhecer as crianças a partir delas mesmas, ou seja, efetuar um exercício de observação, percepção, penetração, participação e interação no aqui e agora delas (MARTINS FILHO, 211).

A partir daí, teremos o espaço das instituições de educação infantil, organizado para contemplar a cultura histórica e socialmente acumulada e, também, para conter as interpretações dessas experiências de conhecimento expressas pelas crianças, as quais chamamos culturas infantis. As múltiplas linguagens - as diferentes formas de expressão -, e não apenas a linguagem oral, podem facilitar nosso acesso às formas de pensar na infância, à lógica das explicações dos fatos, dos fenômenos, das relações em diferentes momentos da formação e apropriação dessa lógica. Ao mesmo tempo, podemos tomar sua expressão por meio de múltiplas linguagens como ponto de partida para uma compreensão que pode ser, também, expressa pela linguagem oral, num formato semelhante a uma entrevista com roteiro aberto em que o pesquisador dialoga com a criança sobre suas teorias de explicação/compreensão da realidade que vai conhecendo. Assim, nas pesquisas com crianças, precisamos nos apropriar das múltiplas linguagens infantis para pensar os procedimentos metodológicos.

Dessa forma, mediado pela compreensão do adulto, o gesto passa a indicativo da vontade da criança, passa a ser uma forma de sua expressão. Depois do gesto, vem a fala, o desenho e as múltiplas linguagens plásticas, corporais, musicais e o faz-de-conta. E por meio de todas essas linguagens, as crianças expressam a forma como interpretam o que conhecem e as experiências que vivem. Está aí a justificativa de nosso título, que chama a atenção para deixar fazer viver a viva voz das crianças.

Podemos, então, dizer que, entre outros, o valor epistemológico dos adultos escutarem a(s) voz(es) das crianças, para as tentarem compreender, nos seus próprios termos, se afigura numa oportunidade para "descerem dos seus sapatos com salto" e virem conhecerem a realidade social a partir delas e da infância. A adesão a este desafio epistemológico requer, no entanto, a problematização de questões de natureza teórica, metodológica e ética a propósito daquela que se tornou uma trindade conceptual de referência da Sociologia da Infância - "as crianças como actores sociais", o "dar voz às crianças" e a "etnografia com crianças" -, sob pena de ela se converter numa nova ortodoxia na pesquisa etnográfica com crianças (FERREIRA, 2002; 2003; 2004). 


\section{Considerações (que nunca serão) Finais: a História continua}

Dia a dia nega-se às crianças o direito de ser crianças. Os fatos, que zombam desse direito, ostentam seus ensinamentos na vida cotidiana. $\mathrm{O}$ mundo trata os meninos ricos como se fossem dinheiro, para que se acostumem a atuar como o dinheiro atua. $\mathrm{O}$ mundo trata os meninos pobres como se fossem lixo, para que se transformem em lixo. E os do meio, os que não são ricos nem pobres, conserva-os atados à mesa do televisor, para que aceitem desde cedo como destino, a vida prisioneira. Muita magia e muita sorte têm as crianças que conseguem ser crianças. (Eduardo Galeano, 1999)

Em nossos estudos e pesquisas, passamos a nos interessar em compreender e dar destaque para as "vozes infantis" nas pesquisas com crianças, avançando para além da natureza das pesquisas sobre crianças. Com intuito de conhecer o que as crianças falam sobre si e conhecer a produção livre das culturas infantis, tomando como ponto de vista o que as próprias crianças nos revelam, temos nos dedicado a romper com os saberes dominantes, saberes hegemônicos, que pretendem definir as crianças por regularidades. Assim, passamos a nos desafiar a observar com atenção as crianças em suas manifestações, sentidos atribuídos à cultura societal e à leitura de significados de conceitos situados, no intuito de captar os variados jeitos de ser e seus estilos de vida, uma pluralidade de modos as crianças pertencentes.

Nesse movimento de estudos e pesquisas, a chave é considerar as crianças como atores sociais. As crianças são seres sociais, com características próprias, inseridas em mundos sociais complexos e heterogêneos, cujas condições de existência são objeto de uma estruturação sustentada em processos de estratificação social, cultural, de gênero e geracional, condições essas continuamente reajustadas pela ação, assente em relações intra e intergeracionais, no interior das quais elas se desenvolvem como indivíduos e como atores sociais plenos.

Assim, vale a pena insistir na ideia de visitar o mundo das crianças para torná-lo especialmente significativo, o que pode contribuir para desnaturalizar o silêncio que, historicamente, circunda as produções culturais das crianças, ou seja, seus modos peculiares de viver e sentir as infâncias. Esperamos que esta publicação possa contribuir com uma dimensão sócio-histórico-cultural de sua formação humana e com a formação de professores da Educação Infantil, construindo e consolidando pesquisas com crianças que sonhem com a beleza do extraordinário e insólito. Talvez, possamos, neste breve texto, chamar a atenção para a importância de deixar fazer viver a viva voz das crianças, proposição que tomamos como centro de nossos argumentos. Ouvir a viva voz das crianças para, nas pesquisas com elas, revelar um olhar diverso sobre a infância. 


\section{REFERÊNCIA}

BRASIL. Ministério da Educação. Conselho Nacional de Educação. Diretrizes Curriculares Nacionais para a Educação Infantil. Brasília, 2009.

BAKHTIN, Mikhail Mikhailovich. Para uma filosofia do ato responsável. Organizado por Augusto Ponzio e Grupo de Estudos dos Gêneros do Discurso - GEGE/UFSCAR. Tradução de Valdemir Miotello e Carlos Alberto Faraco. São Carlos: Pedro \& João Editores, 2011.

BROUGÈRE, Gilles. Culture de masse et culture enfantine. In: ARLEO, Andy et DELALANDE, Julie. Cultures enfantines. Universalité et diversité. Rennes: Presses Universitaires de Rennes, 2010.

BROUGÈRE, G.; ULMANN, A. Aprender pela vida cotidiana. Campinas: Autores Associados, 2012.

BASTIDE, Roger. Prefácio do livro "Folclore e Mudança Social na Cidade de São Paulo" de Florestan Fernandes, 2004.

DELGADO, A. C. \& MULLER, F. Sociologia da Infância: pesquisas com crianças. Educação e Sociedade: Revista de Ciências da Educação, vol.26, São Paulo, Cortez, maio-ago. 2005.

DELGADO, A. C. C. e MARTINS FILHO, A. J. (orgs.). Dossiê "Bebês e crianças bem pequenas em contextos coletivos de educação". Pro-Posições, SP: Unicamp, v.24, n. 3 (72), p. 21-113, set/dez 2013. Disponível: http://www.scielo.br/pdf/pp/v24n3/02.

DELGADO, Ana Cristina Coll; WÜRDIG, Rogério Costa; CAVA, Patrícia Pereira . Interatividade nas culturas da infância: aproximações, amizade e conflitos entre bebês. Revista Educação em Questão (ONLINE), v. 55, p. 144-168, 2017.

DELGADO, Ana Cristina Coll; CASTELLI, C. M.; PORCIUNCULA, F. As programações do mês da criança: ambiguidade e poder na participação dos bebês e crianças pequenas - Infância(s), Educação e Sociedade. Investigar em Educação Revista da Sociedade Portuguesa de Ciências da Educação, v. 4, p. 83-96, 2015.

DELGADO, Ana Cristina Coll. Um encontro com Liane Mozère: perspectivas pós-estruturalistas nos estudos da pequena infãncia. Revista Eletrônica de Educação (São Carlos), v. 7, p. 248-256, 2013.

DELGADO, Ana Cristina \& MÜLLER, Fernanda. Sociologia da Infância: pesquisas com crianças. In: Educação e Sociedade: Revista de Ciências da Educação. Vol. 26, mai/ago. São Paulo: Cortez, 2005.

FARIA, Ana Lúcia G. de. Educação Pré-Escolar e Cultura. $2^{a}$ Ed. Campinas, SP: Editora da Unicamp; São Paulo: Cortez, 1999.

FREIRE, Paulo. Conscientização e Alfabetização: uma nova visão do processo. Revista de Cultura da Universidade do Recife, n.4, 1963.

FERREIRA, Maria M. Martinho. A Gente Aqui o que Gosta mais é de Brincar com os Outros Meninos: as crianças como atores sociais e a (re)organização social do grupo de pares no quotidiano de um Jardim de Infância. Doutorado em Ciências da Educação. Faculdade de Psicologia e Ciências da Educação, Universidade do Porto, 2002.

FERREIRA, Maria Manuela Martinho. Do "avesso" do brincar ou... as relações entre pares, as rotinas da cultura infantil e a construção da(s) ordem(ens) social(ais) instituintes(s) das crianças no jardim-deinfância. In: SARMENTO, Manuel Jacinto \& CERISARA, Ana Beatriz. Crianças e miúdos: perspectivas sociopedagógicas da infância e educação. Edições ASA- Porto- Portugal 2004.

FERREIRA, Manuela. "Branco demasiado" ou... reflexões epistemológicas, metodológicas e éticas acerca da pesquisa com crianças, in Sarmento, M. J. \& Gouvea, M. C. S. "Estudos da Infância, educação e práticas sociais”. Petrópolis, Vozes, p. 143-162, 2003.

FERNANDES, F. As 'Trocinhas' do Bom Retiro. In: FERNANDES, F.. Folclore e mudança social na cidade de São Paulo. Vozes, Petrópolis, 1961.

GOTTLIEB, Alma. Para onde foram os bebês? Em busca de uma antropologia de bebês (e de seus cuidadores). Psicologia USP, São Paulo, n. 20(3), p. 313-336, jul/set 2009. Disponível em: 
http://www.scielo.br/scielo.php?script=sci_arttext\&pid=S0103-65642009000300002.U

GOTTLIEB, Alma. Tudo começa na outra vida: a cultura dos recém-nascidos na África. São Paulo: Fap-Unifesp, 2013.

GALEANO, Eduardo. De Pernas Pro Ar: a escola do mundo ao avesso. Rio de Janeiro: LP\&M, 1999.

ITURRA, Raul. Antropologia da Educação: um percurso investigativo sobre reprodução social. Entrevista concedida a Ana Aire, Ana Lavado e Paula Godinho. Arquivos de Memória. Centro de Estudos de Etnologia Portuguesa, n.6/7, 1999, p.119-138. Este

KRAMER, Sônia. Infância, Cultura Contemporânea e Educação contra a Barbárie. Revista Teias, v.1, n.2, 2000. Disponível em: https://www.e-

publicacoes.uerj.br/index.php/revistateias/article/view/23857/16830

MARTINS FILHO, Altino José. BARBOSA, Maria Carmem Silveira. Das Pesquisas com Crianças ao Encontro da Infância Contemporânea. Revista Reflexão e Ação. Revista do Departamento de Educação e do Curso de Pós-Graduação. v. 18, n.2 (2010).

MARTINS FILHO, Altino José. A vez e a voz das crianças: uma reflexão sobre as produções culturais na infância. Revista Presença Pedagógica, Belo Horizonte, MG, n.61, p.35-45, jan./fev.2005.

MARTINS FILHO, Altino José (Org). Infância Plural: crianças do nosso tempo. Porto Alegre: Mediação, 2006.

MARTINS FILHO, Altino José. Jeitos de ser criança: pesquisas com crianças nos trabalhos apresentados na ANPED de (1999-2009). 32ª . Reunião Anual da ANPED. Minas Gerais, out. 2010.

MARTINS FILHO, Altino José e PRADO, P. D. (Orgs.) Das pesquisas com crianças à complexidade da infância. São Paulo: Autores Associados, 2011.

MARTINS FILHO, Altino José (Org.) Criança pede respeito: ação educativa na creche e na préescola. $2^{\circ}$ Edição. Porto Alegre: Mediação, 2015.

MARTINS FILHO, Altino José; DELGADO, Ana Cristina Coll. A participação dos bebês e das crianças bem pequenas e a prática da docência no contexto da Educação Infantil. Saber \& Educar, v. 1, p. 108-117, 2016.

MARTINS FILHO, A. J. LENI V. D. (Orgs) Lugar da Criança na Escola e na Família: a participação e o protagonismo infantil. $1^{\circ}$ Edição. Porto Alegre: Mediação, 2018.

MARTINS FILHO, Altino José e MARTINS FILHO, Lourival José. Uma Agenda de Estudos sobre as Crianças e a Experiência de Viver a Infância em um Contexto de Educação Coletiva. Revista Humanidades e Inovação, v.6, n.15, 2019. Disponível em:

https://revista.unitins.br/index.php/humanidadeseinovacao/issue/view/59

MARTINS FILHO, Altino José e MARTINS FILHO, Lourival José. Educação Infantil:

Especificidades da docência. Florianópolis: UDESC, 2013.

MARTINS FILHO, Altino José e MARTINS FILHO, Lourival José. Formação de professores e trabalho na Educação Infantil: considerações prepositivas. In: SOUZA, Alba regina Battisti de; SARTORI, Ademilde Silveira; NORONHA, Elisiane Cristina de Souza de Freitas (Orgs) Formação Docentes e práticas pedagógicas: Cenários e trajetórias. Florianópolis: UDESC, 2010.

MELO, Suely Amaral de. O Lugar da Criança na Pesquisa sobre a Infância: alguns posicionamentos na perspectiva da teoria histórico-cultural. In: MARTINS FILHO, Altino José. BARBOSA, Maria Carmem Silveira. Das Pesquisas com Crianças ao Encontro da Infância Contemporânea. Revista Reflexão e Ação. Revista do Departamento de Educação e do Curso de Pós-Graduação. v. 18, n.2 (2010).

SARMENTO, Manuel. Infância contemporânea e educação infantil: uma perspectiva a partir dos direitos da criança. In: Primeira infância no século XXI: direito das crianças de viver, brincar, explorar e conhecer o mundo. Brasil: Oeste, n. 1a, p. 131-148, 2013. 